\title{
The Effect of Zinc Supplementation on Expressed Levels of Peroxisome Proliferator-Activated Receptor Gamma and Glucose Transporter Type 1 Genes in Newborns of Women with Gestational Diabetes Mellitus
}

\author{
Zahra Heidarzadeh ${ }^{1} \cdot$ Mansooreh Samimi $^{2} \cdot$ Seyed Morteza Seifati ${ }^{1}$. \\ Mahmood Dehghani Ashkezari ${ }^{3}$. Shahnaz Ahmadi ${ }^{4,5} \cdot$ Samaneh Mahmoodi $^{2}$. \\ Esmat Aghadavod $^{6} \cdot$ Mehri Jamilian $^{7} \cdot$ Zatollah Asemi $^{6,8}$
}

Received: 10 May 2016 / Accepted: 15 June 2016

(C) Springer Science+Business Media New York 2016

\begin{abstract}
The current study was designed to determine the beneficial effects of zinc supplementation on expressed levels of peroxisome proliferator-activated receptor gamma (PPAR- $\gamma$ ) and glucose transporter type 1 (GLUT1) genes in newborns of women with gestational diabetes mellitus (GDM). This randomized, double-blind, placebo-controlled clinical trial was performed among 40 women with GDM. Patients were randomly allocated to intake either $233 \mathrm{mg}$ zinc gluconate (containing $30 \mathrm{mg}$ zinc) $(n=20)$ or a placebo $(n=20)$ for 6 weeks.
\end{abstract}

Mansooreh Samimi

dr_samimi.2007@yahoo.com

$\triangle$ Zatollah Asemi

asemir@yahoo.com

1 Department of Biology, Ashkezar Branch, Islamic Azad University, Ashkezar, Yazd, Iran

2 Department of Gynecology and Obstetrics, School of Medicine, Kashan University of Medical Sciences, Kashan, Iran

3 Medical Biotechnology Research Center, Ashkezar Branch, Islamic Azad University, Ashkezar, Yazd, Iran

4 Department of Gynecology and Obstetrics, School of Medicine, Iran University of Medical Sciences, Tehran, Iran

5 Department of Gynecology and Obstetrics, School of Medicine, Bushehr University of Medical Sciences, Bushehr, Iran

6 Research Center for Biochemistry and Nutrition in Metabolic Diseases, Kashan University of Medical Sciences, Kashan, Iran

7 Department of Gynecology and Obstetrics, Endocrinology and Metabolism Research Center, School of Medicine, Arak University of Medical Sciences, Arak, Iran

8 Present address: Department of Nutrition, Kashan University of Medical Sciences, Kashan, Iran
PPAR- $\gamma$ and GLUT1 mRNA levels were quantified in umbilical cord blood of newborns of women with GDM. After 6 weeks of intervention, the change in serum zinc levels was greater in women consuming zinc than in the placebo group $(+11.1 \pm 13.4$ vs. $-4.8 \pm 17.3 \mathrm{mg} / \mathrm{dL}, P=0.002)$. Quantitative results of RT-PCR demonstrated that compared with the placebo, zinc supplementation resulted in a significant increase of expressed levels of PPAR- $\gamma$ mRNA $(P<0.001)$ and GLUT1 mRNA $(P<0.001)$ in umbilical cord blood of newborns of women with GDM. Taken together, the current study demonstrated that zinc supplementation for 6 weeks among GDM women increased the mRNA levels of PPAR- $\gamma$ and GLUT1 in their newborns compared with the placebo group.

Keywords Zinc · Supplementation - Gestational diabetes · Peroxisome proliferator-activated receptor gamma · Glucose transporter type 1

\section{Introduction}

Gestational diabetes mellitus (GDM) is defined as insulin resistance or carbohydrate intolerance causing hyperglycemia with onset or first recognition at any time during pregnancy [1]. GDM associated with several maternal complications including preeclampsia, still birth, and requiring operative vaginal delivery or cesarean section, as well as several fetal complications such as prematurity, neonatal hypoglycemia, respiratory distress syndrome and hyperbilirubinemia [2]. In addition, hyperglycemia and altered concentration of fatty acid derivates may result in decreased expression of peroxisome proliferator-activated receptor gamma (PPAR- $\gamma$ ) in the syncytiotrophoblast and the extravillous trophoblast of GDM placentas [3]. Previous studies 
have shown that PPAR- $\gamma$ modulates the expression of several adipocyte-specific genes involved in lipid synthesis and storage, insulin signaling, and adipokine production $[4,5]$.

In addition to zinc antioxidant and anti-inflammatory properties, previous studies reported that zinc appears to be essential for the protective properties of PPAR- $\alpha$ and PPAR- $\gamma$ in vascular endothelial cells [6, 7]. In a study by Zhang et al. [8], it was observed that high levels of $\mathrm{Zn}$ supplementation in weaned piglets increased the mRNA expression levels of PPAR- $\gamma$. In another study, it was reported that zinc deficiency markedly suppressed the mRNA expression of PPAR- $\gamma$ [9]. In addition, placental glucose transporter type 1 (GLUT-1) plays an important function in transporting glucose from mother to fetus [10]. In a study by Ueda et al. [11] was seen that expression levels of placental GLUT-1 mRNA in zinc-deficient pregnant mice was significantly decreased than that observed in control pregnant mice, whereas it unchanged in zincsupplemented pregnant mice.

The DNA-binding domains of PPARs consist of two sets of zinc fingers [12]. The specificity and polarity of PPAR-DNA binding seem to be due at least in part to features in the zinc finger domains of PPARs [13]. We are aware of no randomized controlled trial that evaluated the effects of zinc supplementation on expressed levels of PPAR- $\gamma$ and GLUT- 1 genes in newborns of women with GDM. We hypothesized that zinc supplementation might affect expressed levels of PPAR- $\gamma$ and GLUT-1 genes in newborns of women with GDM. Therefore, the present study was conducted to evaluate the beneficial effects of zinc supplementation on expressed levels of PPAR- $\gamma$ and GLUT-1 genes in newborns of women with GDM.

\section{Subjects and Methods}

\section{Trial Design}

This was a 6-week randomized, double-blind, placebocontrolled clinical trial.

\section{Participants}

Participants were eligible for inclusion if they were 1840 years of age with GDM diagnosed according to the American Diabetes Association criteria referred to the Naghavi Clinic in Kashan, Iran, between December 2015 and April 2016. In the current study, women with GDM diagnosed by "one-step" 2-h 75-g oral glucose tolerance test (OGTT) at 24-28-week gestation and singleton pregnancy were included. Diagnosis of GDM was as follows: pregnant women who met one of the following criteria were considered as having GDM: fasting $\geq 92 \mathrm{mg} / \mathrm{dL}, 1-\mathrm{h} \geq 180 \mathrm{mg} / \mathrm{dL}$, and $2-\mathrm{h}$ $\geq 153 \mathrm{mg} / \mathrm{dL}$ [14]. Women pregnant with preexisting diabetes, psychiatric disease, kidney or liver diseases, chronic hypertension, hypothyroidism, or smokers were excluded.

\section{Ethics Statements}

The present trial was conducted in accordance with the Declaration of Helsinki, and informed consent was received from all participants. The research was approved by the ethics committee of Kashan University of Medical Sciences (KUMS) and was registered in the Iranian website for registration of clinical trials (http://www.irct.ir: IRCT201503055623N42).

\section{Study Design}

At the onset of the study, patients were first matched one-byone according to preintervention BMI $\left(<25\right.$ and $\left.\geq 25 \mathrm{~kg} / \mathrm{m}^{2}\right)$ and weeks of gestation ( $<26$ or $\geq 26$ weeks). Participants were then randomly divided into two groups to receive either zinc supplements $(n=20)$ or placebo $(n=20)$ for 6 weeks. Although the duration of intervention was 6 weeks, all participants were followed up until the delivery. Participants were requested not to change their ordinary physical activity and not to take any nutritional supplements during the 6-week trial. All patients completed 3-day food records and three physical activity records at the study baseline and weeks 2,4 , and 6 of the intervention. Daily macro- and micro-nutrient intakes were analyzed by nutritionist IV software (First Databank, San Bruno, CA). In the current study, physical activity was described as metabolic equivalents (METs) in hours per day. To determine the METs for each patient, we multiplied the times (in hour per day) reported for each physical activity by its related METs coefficient by standard tables [15]. Used tool to measure physical activity was questionnaire.

\section{Intervention}

In the intervention group, participants received $233 \mathrm{mg}$ zinc gluconate (containing $30 \mathrm{mg}$ zinc) supplements and group B received placebo. Due to the lack of evidence about the appropriate dosage of zinc for patients with GDM, we used $30 \mathrm{mg}$ of zinc supplements based on a previous study during pregnancy [16]. Zinc supplements and its placebos (starch) were manufactured by Donyayeh Behesht Pharmaceutical Company (Tehran, Iran) and Barij Essence Pharmaceutical Company (Kashan, Iran), respectively. All zinc and placebo tablets were provided by Barij Essence Pharmaceutical Company in prepacked bottles numbered for each patient according to the randomization sequence.

\section{Treatment Adherence}

Every 2 weeks, subjects were taken enough supplements and placebos to last 3 days after their next scheduled visit and were 
instructed to return all unused supplements and placebos at each visit. The remaining supplements and placebos were counted and subtracted from the number provided to determine the number taken. To increase the compliance, all participants were receiving short messages on their cell phones to take supplements and placebos every day.

\section{Assessment of Anthropometric Variables}

A trained midwife at the maternity clinic did anthropometric measurements at the onset of the study and end-of-trial. Body weight and height (Seca, Hamburg, Germany) were determined while patients were minimally clothed and no shoes. Then, BMI [weight $(\mathrm{kg}) /$ height $^{2}(\mathrm{~m})$ ] was calculated. All anthropometric measures were done by a trained midwife.

\section{Outcomes}

In the present study, the primary outcome was PPAR- $\gamma$ and the secondary study outcome was GLUT1.

\section{Isolation of Lymphocyte Cells}

At first, $10 \mathrm{ml}$ blood samples were obtained from umbilical cord blood of newborns of women with GDM at delivery time. Then, lymphocyte cells were extracted from umbilical cord blood of newborns of women with GDM using a $50 \%$ Percoll (Sigma-Aldrich, Dorset, UK) gradient. Thus, for preparing a stock isotonic Percoll solution, osmolity of the solution was adjusted by adding one part of $10 \times$ concentrated cell culture medium into the nine parts of Percoll. Osmolality of the stock solution was checked by osmometer model 3300 (LabX, EI Cajon, USA). Solution of stock isotonic Percoll (SIP) was diluted by adding normal cell culture medium. The cells of lymphocytes which were at the interface of Percoll and serum were removed by using a Pasteur pipette and washed a few times with phosphate-buffered saline (PBS). Samples were taken for cell count and viability testing by trypan blue, RNA and DNA extraction.

\section{Total RNA Extraction}

In order to RNA extraction, the RNXplus kit (Cinnacolon, Tehran, Iran) was used. Total RNA extraction from all prepared samples was done as recommended protocol by manufacture. After preparation of homogenate, the cells powder was harvested and resuspended in $1 \mathrm{ml}$ of RNAXplus reagent in a clean RNase-free tube. After incubation for $5 \mathrm{~min}$ at room temperature, the sample was pipetted and subsequently treated with addition of $200 \mu \mathrm{l}$ of chloroform. The mixture was incubated at room temperature for $5 \mathrm{~min}$ after shaking rigorously for $15 \mathrm{~s}$. The mixture was centrifuged at $12,000 \mathrm{~g}$ for $15 \mathrm{~min}$, and the aqueous phase containing the RNA was transferred to a clean RNase-free tube. The total RNA was precipitated at room temperature for $15 \mathrm{~min}$. The pellet including total RNA was washed by using $75 \%$ ethanol and centrifuged at $7500 \mathrm{~g}$ for 8 min. After drying ethanol, the RNA pellet was resuspended in $50 \mu \mathrm{l}$ or less of TE buffer. The concentration of total RNA was calculated based on OD 260/280 ration measurements as a means to means to address purity of RNA. To confirm the integrity of extracted RNA, it was electrophoresed. RNA suspension was frozen in $-20^{\circ} \mathrm{C}$ until cDNA making. Following the extraction of the total RNAs from each sample, RNA quantification were performed by UV spectrophotometer. Each samples OD 260/280 ratio between 1.7 and 2.1 was intended that shows no contamination with both protein and DNA.

\section{First Strand cDNA Synthesis Procedure}

The first strand cDNA synthesis can be performed as an individual reaction or as a series of parallel reactions with different RNA templates. Therefore, the reaction mixture can be provided by merging reagents individually or a master mix can be prepared all of the components except template RNA. Depending on the structure of RNA templates, separate steps for RNA denaturation and primer annealing many improve RT-PCR results. The isolated RNA was reverse transcribed to cDNA library using Moloney murine leukemia virus (MMLV) reverse transcriptase (RT). Reverse transcription was performed with random primers.

\section{Gene Expression}

Expressed levels of PPAR- $\gamma$ and Glut- 1 were evaluated by quantitative RT-PCR, using the LightCycler technology (Roche Diagnostics, Rotkreuz, Switzerland) with SYBR green detection and Amplicon Kit (Table 1). Glyceraldehyde-3-phosphate dehydrogenase (GAPDH) primers were used as a loading control (forward AAGCTCATTTCCTGGTATGACAACG; reverse TCTTCCTCTTGTGCTCTTGCTGG). As template, approximately 50 ng cDNA was applied in a quantitative real-time RT-PCR, and the signals were detected using a real-time PCR system. All reactions were run in duplicates. All primers were designed using Primer Express Software (Applied Biosystems) and Beacon designer software then, purchased from Takaposizt Company, Iran. Relative transcription levels were calculated using Pffafi method or $2^{-\Delta \Delta \mathrm{CT}}$. Normalization of gene expression data is used to correct sample-to-sample variation. Starting material obtained from different individuals usually varies in tissue mass or cell number, RNA integrity or quantity, or experimental treatment. The ideal control gene should be expressed in an unchanging fashion regardless of experimental conditions, including different tissue or cell types, developmental stage, or sample treatment. Because there is no one gene that meets this criterion for every 
Table 1 Specific primers used for real-time quantitative PCR

\begin{tabular}{llcc}
\hline Gene & Primer & Product size $(\mathrm{bp})$ & Annealing temperature $\left({ }^{\circ} \mathrm{C}\right)$ \\
\hline GAPDH & $\begin{array}{l}\text { F: AAGCTCATTTCCTGGTATGACAACG } \\
\text { R: TCTTCCTCTTGTGCTCTTGCTGG }\end{array}$ & 126 & 61.3 \\
PPAR- $\gamma$ & $\begin{array}{l}\text { F: ATGACAGACCTCAGACAGATTG } \\
\text { R: AATGTTGGCAGTGGCTCAG }\end{array}$ & 210 & 54 \\
GLUT1 & $\begin{array}{l}\text { F: TATCTGAGCATCGTGGCCAT } \\
\text { R: AAGACGTAGGGACCACACAG }\end{array}$ & 238 & 62.1 \\
& & & \\
\hline
\end{tabular}

GAPDH glyceraldehyde-3-phosphate dehydrogenase, GLUT1 glucose transporter type 1, PPAR- $\gamma$ peroxisome proliferator-activated receptor gamma experimental condition, it is necessary to validate the expression stability of a control gene for the specific requirements of an experiment prior to its use for normalization. Also, GAPDH gene (housekeeping gene) was used for normalization.

\section{Assessment of Zinc Levels}

A serum zinc concentration at the study baseline and 6 weeks after intervention among GDM women was evaluated using zinc kit (Elitech, Puteaux, France).

\section{Randomization}

Randomization assignment was done using computergenerated random numbers. Randomization and allocation were concealed from the researchers and participants until the final analyses were completed. The randomized allocation sequence, enrolling participants and allocating them to interventions were conducted by a trained staff at the clinic.

\section{Statistical Analysis}

We applied the Kolmogrov-Smirnov test to examine if variables were normally distributed. Independent samples Student's $t$ test was used to detect differences in general characteristics and macro- and micro-nutrients dietary intakes between the two groups. To determine the effects of zinc supplementation on PPAR- $\gamma$ and GLUT1 mRNA levels, we used independent samples Student's $t$ test. All statistical analyses were done using the Statistical Package for Social Science version 17 (SPSS Inc., Chicago, IL, USA).

\section{Results}

At the study baseline, we recruited 50 patients; however, 10 subjects were excluded from the study because of not meeting inclusion criteria $(n=6)$ and needed to start insulin therapy $(n=4)$. In the current study, 40 participants [zinc $(n=20)$ and placebo $(n=20)$ ] completed the trial (Fig. 1). On average, the rate of compliance in the present study was high, such that $100 \%$ of zinc supplements were
Fig. 1 Summary of patient flow diagram

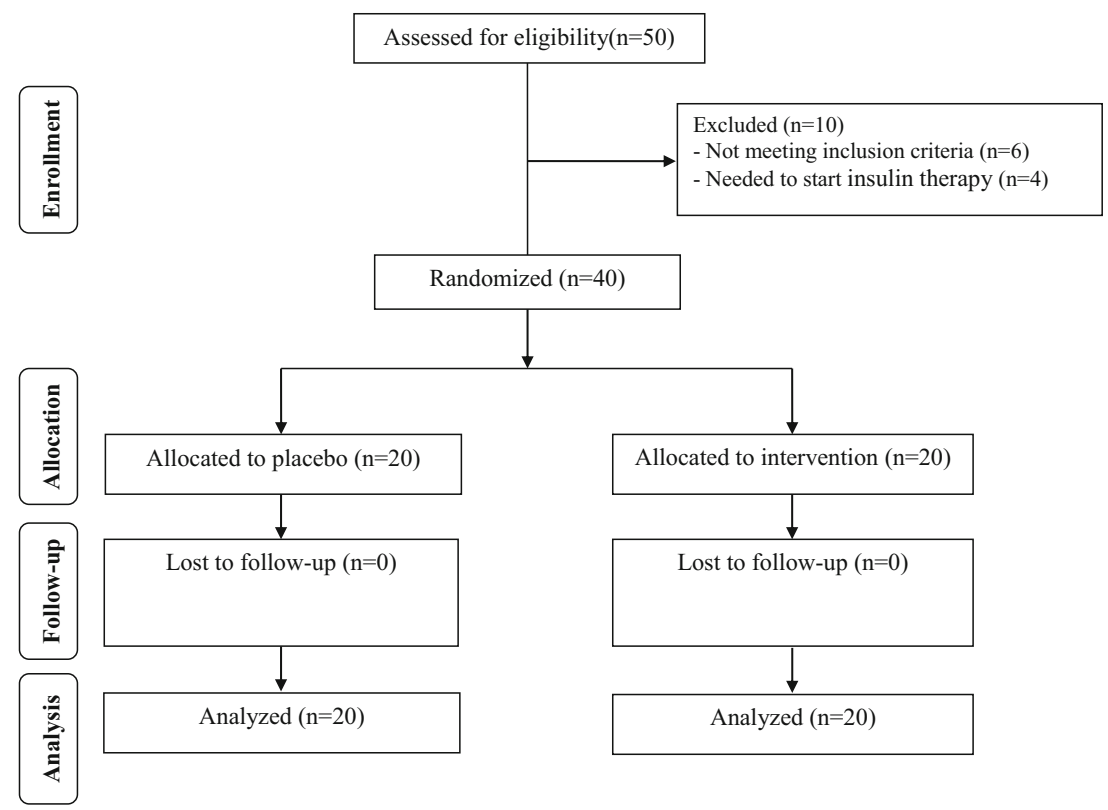


taken throughout the study in both groups. No side effects were reported following the consumption of zinc supplements in women with GDM throughout the study.

No significant difference existed in the anthropometric measures before and after the intervention between the two groups (data not shown).

Comparison of total calorie intake, macro- and micronutrients between the two groups based on the 3-day dietary records throughout the study no statistically significant difference was shown (data not shown).

After 6 weeks of intervention, the change in serum zinc levels was greater in women consuming zinc than in the placebo group $(+11.1 \pm 13.4$ vs. $-4.8 \pm 17.3 \mathrm{mg} / \mathrm{dL}, P=0.002)$. Quantitative results of RT-PCR demonstrated that compared with the placebo, zinc supplementation resulted in a significant increase of expressed levels of PPAR- $\gamma$ mRNA $(P<0.001)$ in umbilical cord blood of newborns of women with GDM (Fig. 2).

A significant increase in expressed levels of GLUT1 mRNA $(P<0.001)$ in umbilical cord blood of newborns of women with GDM following the supplementation of zinc compared with the placebo among GDM women (Fig. 3).

\section{Discussion}

This study assessed the beneficial effects of zinc supplementation on expressed levels of PPAR- $\gamma$ and GLUT1 genes in newborns of women with GDM. The current study shown that zinc supplementation for 6 weeks among GDM women increased the mRNA levels of PPAR- $\gamma$ and GLUT1 in their newborns compared with the placebo group. To our knowledge, the current study is the first that reports the beneficial effects of zinc supplementation on expressed levels of PPAR- $\gamma$ and GLUT1 genes in newborns of women with GDM.

Pregnant and GDM women are sensitive to micronutrient deficiency, inflammation, and various fetal and maternal aberrations $[17,18]$. Our study demonstrated that zinc supplementation

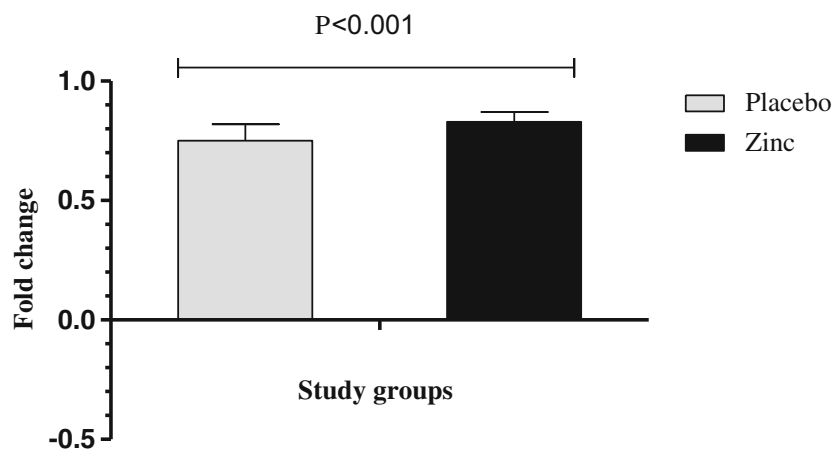

Fig. 2 Effect of 6-week supplementation with zinc or placebo on expression ratio of PPAR- $\gamma$ gene in peripheral blood mononuclear cells of newborns of women with GDM. GDM gestational diabetes mellitus. $P P A R-\gamma$ peroxisome proliferator-activated receptor gamma
$\mathrm{P}<0.001$

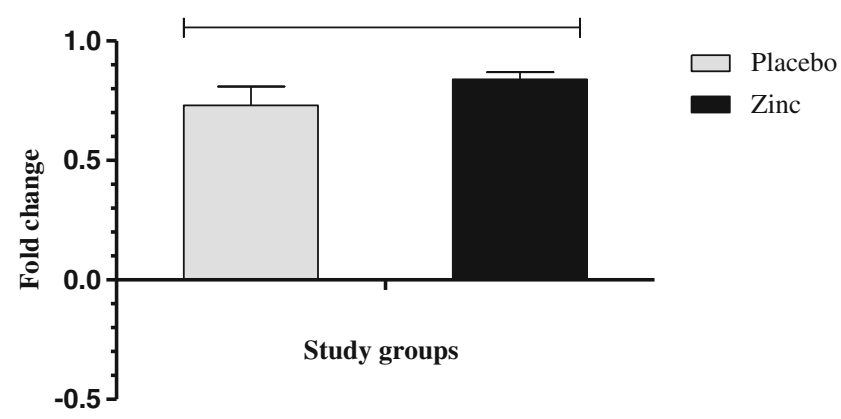

Fig. 3 Effect of 6-week supplementation with zinc or placebo on expression ratio of GLUT1 gene in peripheral blood mononuclear cells of newborns of women with GDM. GLUT1 glucose transporter type 1. GDM, gestational diabetes mellitus

for 6 weeks among GDM women increased the mRNA levels of PPAR- $\gamma$ in their newborns compared with the placebo group. In line with our findings, in a study by Zhang et al. [8], it was observed that the mRNA levels of PPAR- $\gamma$ were significantly higher in all zinc treatments $(250,380,570$, and $760 \mathrm{mg}$ zinc $/ \mathrm{kg}$ of the basal diet) in weaned piglets. In addition, zinc supplementation increased PPAR- $\gamma$ expression and activation as well as downregulated interleukin (IL)-6 expression and production in porcine endothelial cells [9]. Previous studies have shown that zinc deficiency induces PPAR- $\gamma$ signaling, pro-inflammatory phenotype and atherosclerosis in vascular endothelial cells and LDL-receptor knockout mice [7, 19]. However, no significant difference was observed for PPAR- $\gamma$ activity after low-zinc intake $(0.5-1.5 \mathrm{mg} / \mathrm{kg})$ in mice fed with a high-fat diet [20]. PPAR- $\gamma$ is a member of the nuclear receptor superfamily and regulates the expression of several genes encoding proteins involved in adipocyte differentiation, fatty acid storage and glucose metabolism [21]. Downregulation PPAR- $\gamma$ plays an important role in the pathology of numerous diseases such as diabetes, atherosclerosis, and cancer [22]. The mechanisms and regulation of PPAR- $\gamma$ signaling by zinc remain mostly unknown. The current study clearly showed that zinc is critical for normal and constitutive PPAR- $\gamma$ activity and that zinc deficiency can lead to dysfunction of PPAR- $\gamma$ signaling. Previous reports have demonstrated that zinc may be required for the expression of PPAR- $\gamma$ as a zinc finger protein $[23,24]$ because the DNA-binding domain of PPAR- $\gamma$ contains a zinc finger motif, which plays an important role in the specificity and polarity of PPAR receptor DNA binding. Furthermore, the direct involvement of zinc as a functional component of zinc fingers in the regulation of PPAR- $\gamma$ was supported by Meerarani et al. [9] study, which clearly indicated that the PPAR- $\gamma$ agonist-mediated downregulation of the transcription factor NF-kB was impaired during zinc deficiency.

The current study revealed that zinc administration for 6 weeks among GDM women increased the mRNA levels of GLUT1 in their newborns compared with the placebo group. In a study by Ueda et al. [11], it was seen that at day 17 of gestation, the expression of placental GLUT1 mRNA 
did not affect following the supplementation with zinc, but that observed in zinc-deficient mice significantly decreased to $70 \%$ of that observed in control mice. However, zinc element did not influence expressed levels of GLUT1 in C6 rat glioma and GP8 rat brain endothelial cells [25]. Some studies have demonstrated that neonates who had mothers with PGDM had higher rates of neonatal hypoglycemia [26, 27]. Placental GLUT1 plays a key role in transporting glucose from mother to fetus [10]. Therefore, supplying glucose for use as a placental and fetal fuel may be decreased in zincdeficient pregnant women. In a study by Wang et al. [28], it was demonstrated that zinc levels in serum of women with GDM compared with normal pregnant women had a decreasing trend. However, the regulation of placental GLUT1 expression remains unclear [29]. In accordance with the importance of zinc for fetal development, zinc deficiency during pregnancy has reported that is associated with congenital malformations and embryonic and fetal deaths [30].

Strengths of the current study were the blinding of participants and without dropout rate. The current study has some limitations. First of the all, the duration of this study was low. We did not continue zinc supplementation up to delivery time. Future studies with longer duration of the intervention and bigger sample size are needed to confirm the validity of our findings. Second, we did not evaluate the effects of zinc supplementation on other expressed levels including markers related with inflammatory factors and biomarkers of oxidative stress.

\section{Conclusions}

Taken together, the current study demonstrated that zinc supplementation for 6 weeks among GDM women increased the mRNA levels of PPAR- $\gamma$ and GLUT1 in their newborns compared with the placebo group. Findings of the current study suggest that zinc supplementation may confer advantageous therapeutic potential for patients with GDM.

Acknowledgments This study was supported by a grant from the Vicechancellor for Research, KUMS, and Iran.

Author Contributions ZH, MS, S-MS, MD-A, ShA, SM, EA, and MJ contributed in conception, data collection, and manuscript drafting. ZA contributed in conception, design, and statistical analysis.

Compliance with Ethical Standards The present trial was conducted in accordance with the Declaration of Helsinki, and informed consent was received from all participants. The research was approved by the ethics committee of Kashan University of Medical Sciences (KUMS) and was registered in the Iranian website for registration of clinical trials (http://www.irct.ir: IRCT201503055623N42).

Conflict of Interest The authors declare that they have no conflict of interest.

Clinical Registration $\quad$ www.irct.ir as IRCT201503055623N42.

\section{References}

1. Voormolen DN, Abell SK, James R, Hague WM, Mol BW (2016) Diagnostic criteria and treatment for gestational diabetes mellitus. Semin Reprod Med 34:102-109

2. Metzger BE, Persson B, Lowe LP et al (2010) Hyperglycemia and adverse pregnancy outcome study: neonatal glycemia. Pediatrics 126:e1545-e1552

3. Knabl J, Huttenbrenner R, Hutter S et al (2014) Peroxisome proliferator-activated receptor-gamma (PPARgamma) is down regulated in trophoblast cells of gestational diabetes mellitus (GDM) and in trophoblast tumour cells BeWo in vitro after stimulation with PPARgamma agonists. J Perinat Med 42:179-187

4. Lehrke M, Lazar MA (2005) The many faces of PPARgamma. Cell 123:993-999

5. He W, Barak Y, Hevener A et al (2003) Adipose-specific peroxisome proliferator-activated receptor gamma knockout causes insulin resistance in fat and liver but not in muscle. Proc Natl Acad Sci U S A 100:15712-15717

6. Reiterer G, Toborek M, Hennig B (2004) Peroxisome proliferator activated receptors alpha and gamma require zinc for their antiinflammatory properties in porcine vascular endothelial cells. J Nutr 134:1711-1715

7. Reiterer G, MacDonald R, Browning JD et al (2005) Zinc deficiency increases plasma lipids and atherosclerotic markers in LDLreceptor-deficient mice. J Nutr 135:2114-2118

8. Zhang HB, Wang MS, Wang ZS et al (2014) Supplementation dietary zinc levels on growth performance, carcass traits, and intramuscular fat deposition in weaned piglets. Biol Trace Elem Res 161:69-77

9. Meerarani P, Reiterer G, Toborek M, Hennig B (2003) Zinc modulates PPARgamma signaling and activation of porcine endothelial cells. J Nutr 133:3058-3064

10. Kamei Y, Tsutsumi O, Yamakawa A, Oka Y, Taketani Y, Imaki J (1999) Maternal epidermal growth factor deficiency causes fetal hypoglycemia and intrauterine growth retardation in mice: possible involvement of placental glucose transporter GLUT3 expression. Endocrinology 140:4236-4243

11. Ueda H, Nakai T, Konishi T, Tanaka K, Sakazaki F, Min KS (2014) Effects of zinc deficiency and supplementation on leptin and leptin receptor expression in pregnant mice. Biol Pharm Bull 37:581-587

12. Hihi AK, Michalik L, Wahli W (2002) PPARs: transcriptional effectors of fatty acids and their derivatives. Cell Mol Life Sci 59:790-798

13. Hsu MH, Palmer CN, Song W, Griffin KJ, Johnson EF (1998) A carboxyl-terminal extension of the zinc finger domain contributes to the specificity and polarity of peroxisome proliferator-activated receptor DNA binding. J Biol Chem 273:27988-27997

14. Metzger BE, Gabbe SG, Persson B et al (2010) International association of diabetes and pregnancy study groups recommendations on the diagnosis and classification of hyperglycemia in pregnancy. Diabetes Care 33:676-682

15. Ainsworth BE, Haskell WL, Whitt MC et al (2000) Compendium of physical activities: an update of activity codes and MET intensities. Med Sci Sports Exerc 32:S498-S504

16. Hamadani JD, Fuchs GJ, Osendarp SJ, Huda SN, GranthamMcGregor SM (2002) Zinc supplementation during pregnancy and effects on mental development and behaviour of infants: a follow-up study. Lancet 360:290-294

17. Asemi Z, Tabassi Z, Samimi M, Fahiminejad T, Esmaillzadeh A (2013) Favourable effects of the Dietary Approaches to Stop Hypertension diet on glucose tolerance and lipid profiles in gestational diabetes: a randomised clinical trial. Br J Nutr 109:2024-2030

18. Samimi M, Asemi Z, Taghizadeh M, Azarbad Z, RahimiForoushani A, Sarahroodi S (2012) Concentrations of serum zinc, hemoglobin and ferritin among pregnant women and their effects on birth outcomes in Kashan, Iran. Oman Med J 27:40-45 
19. Shen H, Oesterling E, Stromberg A, Toborek M, MacDonald R, Hennig B (2008) Zinc deficiency induces vascular proinflammatory parameters associated with NF-kappaB and PPAR signaling. J Am Coll Nutr 27:577-587

20. Liu MJ, Bao S, Bolin ER et al (2013) Zinc deficiency augments leptin production and exacerbates macrophage infiltration into adipose tissue in mice fed a high-fat diet. J Nutr 143:1036-1045

21. Grindflek E, Sundvold H, Lien S, Rothschild MF (2000) Rapid communication: physical and genetic mapping of the Peroxisome Proliferator Activated Receptor gamma (PPAR-gamma) gene to porcine chromosome 13. J Anim Sci 78:1391-1392

22. Strakova N, Ehrmann J, Bartos J, Malikova J, Dolezel J, Kolar Z (2005) Peroxisome proliferator-activated receptors (PPAR) agonists affect cell viability, apoptosis and expression of cell cycle related proteins in cell lines of glial brain tumors. Neoplasma 52:126-136

23. Evans-Galea MV, Blankman E, Myszka DG, Bird AJ, Eide DJ, Winge DR (2003) Two of the five zinc fingers in the Zap1 transcription factor DNA binding domain dominate site-specific DNA binding. Biochemistry 42:1053-1061

24. Bittel DC, Smirnova IV, Andrews GK (2000) Functional heterogeneity in the zinc fingers of metalloregulatory protein metal response element-binding transcription factor-1. J Biol Chem 275:37194 37201

25. Ilouz R, Kaidanovich O, Gurwitz D, Eldar-Finkelman H (2002) Inhibition of glycogen synthase kinase-3beta by bivalent zinc ions: insight into the insulin-mimetic action of zinc. Biochem Biophys Res Commun 295:102-106

26. Abu-Heija AT, Al-Bash M, Mathew M (2015) Gestational and pregestational diabetes mellitus in Omani women: comparison of obstetric and perinatal outcomes. Sultan Qaboos Univ Med J 15: e496-e500

27. Easmin S, Chowdhury TA, Islam MR et al (2015) Obstetric outcome in early and late onset gestational diabetes mellitus. Mymensingh Med J 24:450-456

28. Wang $Y$, Tan M, Huang $Z$ et al (2002) Elemental contents in serum of pregnant women with gestational diabetes mellitus. Biol Trace Elem Res 88:113-118

29. Ma Y, Zhu MJ, Uthlaut AB et al (2011) Upregulation of growth signaling and nutrient transporters in cotyledons of early to midgestational nutrient restricted ewes. Placenta 32:255-263

30. Uriu-Adams JY, Keen CL (2010) Zinc and reproduction: effects of zinc deficiency on prenatal and early postnatal development. Birth Defects Res B Dev Reprod Toxicol 89:313-325 